\title{
The impact of early-years provision in Children's Centres (EPICC) on child cognitive and socio-emotional development: study protocol for a randomised controlled trial
}

Lynne Murray ${ }^{1,2^{*}}$, Susie Jennings ${ }^{1}$, Alicia Mortimer ${ }^{1}$, Amber Prout $^{1}$, Edward Melhuish $^{3}$, Claire Hughes ${ }^{4}$, John Duncan ${ }^{5}$, Joni Holmes ${ }^{5}$, Corinne Dishington ${ }^{6}$ and Peter J. Cooper ${ }^{1,2^{*}}$

\begin{abstract}
Background: There are marked disparities between pre-school children in key skills affecting school readiness, disparities that commonly persist and influence children's later academic achievements, employment, and adjustment. Much of this disparity is linked to socio-economic disadvantage and its impact on the home learning environment. Children's Centres are an ideal context in which to implement and evaluate programmes to address this problem. They principally serve the $30 \%$ worst areas on the Indices of Deprivation Affecting Children, providing for families from the antenatal period up to age 5 years, aiming to promote parenting skills and provide care for children.
\end{abstract}

Methods: We are conducting a randomised controlled trial, based in Children Centres, to evaluate a parenting intervention for caregivers of children between 28 and 45 months of age. The intervention provides training to parents in dialogic book-sharing. The training is run by a facilitator who sees parents in small groups, on a weekly basis over 7 weeks. The study is a cluster randomised controlled trial. Twelve of the Children's Centres in the town of Reading in the UK have been randomly assigned to an index or control condition. The primary outcome is child cognition (language, attention, and executive function); and secondary outcomes are child social development, behaviour problems, and emotion regulation, parenting during book-sharing and problem solving and parental child behaviour management strategies. Data are collected at baseline, post-intervention and 4-6 months post-intervention.

Discussion: The Impact of Early-years Provision in Children's Centres trial (EPICC) aims to evaluate the impact of an early parenting intervention on several key risk factors for compromised child development, including aspects of parenting and child cognition, social development, behaviour problems and emotion regulation. The study is being carried out in Children's Centres, which largely serve the most disadvantaged families in the UK. Since the intervention is brief and, with modest levels of training, readily deliverable within Children's Centres and similar early childcare provision centres, demonstration that it is of benefit to child cognition, socio-emotional development and behaviour would be important.

\footnotetext{
* Correspondence: lynne.murray@rdg.ac.uk; p.j.cooper@rdg.ac.uk

'University of Reading, Reading, UK

Full list of author information is available at the end of the article
}

(c) The Author(s). 2018 Open Access This article is distributed under the terms of the Creative Commons Attribution 4.0 International License (http://creativecommons.org/licenses/by/4.0/), which permits unrestricted use, distribution, and reproduction in any medium, provided you give appropriate credit to the original author(s) and the source, provide a link to the Creative Commons license, and indicate if changes were made. The Creative Commons Public Domain Dedication waiver (http://creativecommons.org/publicdomain/zero/1.0/) applies to the data made available in this article, unless otherwise stated. 
(Continued from previous page)

Trial registration: ISRCTN Registry, ISRCTN28513611. Registered on 28 March 2017.

This is version 1 of the protocol for the EPICC trial.

Keywords: Early child development, Cognitive development, Social development, Emotion regulation, Executive function, Parenting intervention, Book-sharing, Dialogic reading, Children's Centres

\section{Background}

There are marked disparities between pre-school children in key skills affecting school readiness (e.g., language, attention, regulation of behaviour and emotions and social relationships) $[1,2]$. Much of this disparity is linked to socio-economic disadvantage and its impact on the home learning environment [3-5]. These early childhood effects of disadvantage are important, as they commonly persist and influence children's later academic achievements, employment and adjustment, thereby perpetuating inter-generational cycles of disadvantage [6, 7]. In the UK, Children's Centres represent an ideal context in which to implement and evaluate programmes that could address this problem. They were initially established to serve the $30 \%$ worst areas on the Indices of Deprivation Affecting Children (IDACI), with wider roll out subsequently. They provide for families from the antenatal period up to age 5 years, aiming to promote parenting skills and provide care for children. Research shows that such pre-school provision can be of particular benefit to children's later performance and functioning at school when staff are highly trained and support parents' involvement in their children's learning at home [8]. One parenting skill that stands to be of particular benefit to children's development is "dialogic reading", or "dialogic book-sharing". This is a method of supporting an infant or young child with a picture book in a way that sensitively follows and supports the child's interests and engages them actively in a reciprocal interaction. Parental reading or sharing books with children is one of the best predictors of children's educational outcomes, even when account is taken of family factors like social class and parental education (e.g., [9]). Importantly, disadvantaged parents are less likely than others to share books with their children, and when they do, they tend not to use the "dialogic" techniques that are particularly helpful to child development, and therefore they may be especially likely to benefit from supportive guidance in using these techniques. Indeed, the evidence (principally from North America) clearly shows that it is possible to train parents in good dialogic book-sharing practices, using relatively brief interventions, with consequent benefits for their children's development [10-12]. Consistent with these previous intervention studies, in a deprived South African population we have shown that our dialogic book-sharing training programme brings about significant benefits to parental sensitivity and reciprocity whilst sharing picture books, and to the child's attention and receptive and expressive language $[13,14]$. Importantly, and extending previous research, we found these gains in child development to be mediated by the improvements in parenting [15]. Further, recent examination of our data indicates that the intervention is especially beneficial for children who are the most disadvantaged.

In our South Africa study we also found, in preliminary analyses, significant benefit of training in dialogic book-sharing to young children's social understanding and empathy [15]. In order to enhance the benefit of the programme to these child outcomes, we have further integrated into our training programme key principles arising from evidence from naturalistic, observational studies concerning the associations between specific dimensions of parental talk (including during book-sharing), and child socio-emotional development [16]. For example, research shows that when parents talk to their children about emotions and mental states, something which occurs more during book-sharing than in other contexts, children have better emotional understanding and skills in theory of mind, with these benefits even evident in their peer relationships [17-19]. Based on such findings, we have developed our dialogic book-sharing programme beyond the standard focus on cognitive and language outcomes to support parents to use the specific techniques that additionally promote child socio-emotional understanding and pro-social behaviour. This involves careful selection of books that afford parent-child talk about emotions and mental states (e.g., intentions, beliefs and perspectives) and relationships, along with accompanying guidance for parents in how best to support their child's awareness and understanding of such content. Importantly, we also prioritise books that are largely free of text, in order to maximise free-ranging discussion of the picture content, and to facilitate the use of our programme's books by parents who may not be literate themselves. We have also incorporated elements into the programme to promote executive functioning skills (e.g., making comparisons, highlighting mutually exclusive relationships, linking elements of depicted content together and to the overall story line) [20]. These original contributions to standard book-sharing practice stand to be of considerable potential benefit to children's capacity to adjust to the multiple 
socio-emotional demands of the school environment, adding benefits to the linguistic and cognitive skills previously established to be associated with parental training in book-sharing.

Given the accumulation of research showing the benefits of book-sharing, it is striking that no systematic evaluation of training parents in such structured dialogic book-sharing programmes has been conducted in the UK. Indeed, to our knowledge, although the provision of books for young children and encouragement to parents to share them with their children is widespread, no such evidence-based, systematic and structured training programme is currently delivered in UK Children's Centres or other UK contexts attempting to serve the needs of more deprived families.

We are conducting and evaluating our programme in the UK context. Accordingly, we secured the collaboration of the Children Centres in the town of Reading, carried out pilot work, and established the programme's acceptability to both staff and parents. We are now delivering the programme to parents in these Children's Centres, and evaluating the impact on parenting and child cognition, socio-emotional development, and behaviour, both following the intervention and at follow up 4-6 months later. The study time line is shown in Fig. 1.

\section{Current trial}

The study aims are to determine, via a randomised controlled trial (RCT), the impact within Children's Centres, of providing carers with training in supportive and reciprocal dialogic book-sharing with their young children. In particular, we aim to determine the impact of the training on child cognitive development (primary outcome), on child social development, behaviour problems and emotional regulation (secondary outcomes), and on parenting (secondary outcome).

\section{Methods}

\section{Study design}

The study is a cluster RCT. Reading has 13 Children's Centres, but one is an outlier in terms of the socio-demographic profile of both ward and attenders. The remaining 12 Centres have been randomly assigned to the index condition (6 Centres), which is receiving training in dialogic book-sharing, and a control condition (6 Centres) receiving the normal input from the Children's Centres. Data are being collected at baseline, post-intervention, and at 4-6 month follow up.

\section{Hypotheses}

Primary hypothesis Compared to control group children whose carers receive no additional intervention, children whose carers receive the programme will show evidence of significantly better cognitive outcomes (i.e., observed language, sustained attention and executive function, and parent report).

Secondary hypotheses Compared to control group children, intervention group children will evidence significantly:

1. Better social development (observed theory of mind and emotional understanding, empathy and altruism, and parent report);

2. Fewer behavioural problems (observed defiance and parent report);

3. Better emotional regulation (observed behaviour under challenge and parent report); and compared to control group caregivers, caregivers who receive the programme will evidence significantly -

4. More sensitivity, reciprocity, mental state talk, and cognitive scaffolding with their children (observed behaviours);

5. Better behavioural management strategies (observed behaviour and parent report); and improvement in $-$

6. Child cognition will be mediated by enhancement of caregiver sensitivity, reciprocity, and cognitive scaffolding;

7. Child social development will be mediated by enhancement of caregiver sensitivity, reciprocity and mental state talk; and

8. Child behavioural problems and emotional regulation will be mediated by enhancement of sensitivity, reciprocity, mental state talk and behaviour management strategies.

\section{Collaboration}

The EPICC study is a collaborative project between the University of Reading, Oxford University, Cambridge University and the Reading Borough Council. The project is funded by the Nuffield Foundation, with further support from the Medical Research Council (MRC) Cognition and Brain Sciences Unit. The Funders have no involvement in the study design or implementation.

\section{Study setting}

The study is being conducted in Children's Centres in the town of Reading in the UK. The Reading population is representative of the general UK population, including its multi-ethnic communities and significant areas of deprivation. The local authority is strongly committed to Children's Centres and to the promotion of the development of the 


\begin{tabular}{|c|c|c|c|c|c|c|}
\hline \multirow[b]{3}{*}{ TIMEPOINT ${ }^{\star *}$} & \multicolumn{6}{|c|}{ STUDY PERIOD } \\
\hline & \multirow{2}{*}{$\begin{array}{l}\text { Allocation } \\
-4 \text { weeks }\end{array}$} & \multirow{2}{*}{$\begin{array}{l}\text { Enrolment } \\
\text { Weeks 1-38 }\end{array}$} & \multicolumn{3}{|c|}{ Post-allocation } & \multirow{2}{*}{$\begin{array}{c}\text { Close-out } \\
\begin{array}{c}\text { Follow up } \\
\text { assessment } \\
\text { Weeks } 38-64\end{array}\end{array}$} \\
\hline & & & $\begin{array}{c}\text { Baseline } \\
\text { assessment } \\
\text { Weeks 1-38 }\end{array}$ & $\begin{array}{l}\text { Intervention } \\
\text { Weeks 5-21 }\end{array}$ & $\begin{array}{c}\text { Post } \\
\text { intervention } \\
\text { assessment } \\
\text { Weeks 17-56 }\end{array}$ & \\
\hline \multicolumn{7}{|l|}{ ENROLMENT: } \\
\hline \multirow{2}{*}{$\begin{array}{l}\text { Eligibility screen } \\
\text { Informed consent }\end{array}$} & & $\mathrm{x}$ & & & & \\
\hline & & $\mathrm{x}$ & & & & \\
\hline Allocation & $\mathrm{x}$ & & & & & \\
\hline \multicolumn{7}{|l|}{ INTERVENTIONS: } \\
\hline $\begin{array}{r}\text { Booksharing } \\
\text { training }\end{array}$ & & & & $x$ & & \\
\hline \multicolumn{7}{|l|}{ ASSESSMENTS: } \\
\hline \multirow{2}{*}{$\begin{array}{r}\text { Language (primary } \\
\text { outcome) } \\
\text { Attention (primary } \\
\text { outcome) }\end{array}$} & & & $x$ & & $x$ & $x$ \\
\hline & & & $x$ & & $x$ & $x$ \\
\hline \multirow{5}{*}{$\begin{array}{r}\text { Executive function } \\
\text { (primary outcome) } \\
\text { Theory of Mind } \\
\text { (secondary } \\
\text { outcome) } \\
\text { Empathy } \\
\text { (secondary } \\
\text { outcome) } \\
\text { Altruism } \\
\text { (secondary } \\
\text { outcome) } \\
\text { Prosocial } \\
\text { behaviour } \\
\text { (secondary } \\
\text { outcome) }\end{array}$} & & & $x$ & & $x$ & $x$ \\
\hline & & & $\mathrm{x}$ & & $\mathrm{x}$ & $\mathrm{x}$ \\
\hline & & & $\mathrm{x}$ & & $x$ & $\mathrm{x}$ \\
\hline & & & & & & $x$ \\
\hline & & & $x$ & & $x$ & $x$ \\
\hline $\begin{array}{r}\text { Child behaviour } \\
\text { problems } \\
\text { (secondary } \\
\text { outcome) }\end{array}$ & & & $\mathrm{x}$ & & $\mathrm{x}$ & $x$ \\
\hline $\begin{array}{r}\text { Child emotion } \\
\text { regulation } \\
\text { (secondary } \\
\text { outcome) }\end{array}$ & & & $x$ & & $x$ & $x$ \\
\hline $\begin{array}{r}\text { Parental sensitivity } \\
\text { and reciprocity } \\
\text { (secondary } \\
\text { outcome) }\end{array}$ & & & $\mathrm{x}$ & & $x$ & \\
\hline $\begin{array}{r}\text { Parental cognitive } \\
\text { scaffolding } \\
\text { (secondary } \\
\text { outcome) }\end{array}$ & & & $x$ & & $x$ & \\
\hline $\begin{array}{r}\text { Parental mental } \\
\text { state talk } \\
\text { (secondary } \\
\text { outcome) }\end{array}$ & & & $\mathrm{x}$ & & $\mathrm{x}$ & \\
\hline $\begin{array}{r}\text { Parental } \\
\text { behavioural } \\
\text { management } \\
\text { strategies }\end{array}$ & & & $\mathrm{x}$ & & $x$ & $\mathrm{x}$ \\
\hline $\begin{array}{r}\text { Parental stress } \\
\text { and mood }\end{array}$ & & & $\mathrm{x}$ & & $\mathrm{x}$ & $x$ \\
\hline
\end{tabular}

Fig. 1 Schedule of enrolment, interventions and assessments. * Recommended content can be displayed using various schematic formats. See Additional file 1 SPIRIT 2013 Explanation and Elaboration for examples from protocols. **List specific timepoints in this row

under-fives. It is notable that attendance at Children Centres among the most deprived segments of the Reading population has consistently been maintained right through children's first 3-4 years, rather than dropping off as pupil premiums become available for parents to use in other child care contexts, as occurs elsewhere in the country [21].

\section{Eligibility criteria Sample}

The sample comprises carers (mainly mothers) of children attending the Reading Children Centres, whose children are aged 28-45 months at recruitment and where English is spoken at home. There are 3074 children under 5 years of age living in Reading within the $20 \%$ 
most deprived local super output areas (LSOAs) [22], representing $25 \%$ of all Reading children of this age. The 12 participating Children's Centres in Reading are situated in these areas. They target the most vulnerable families in these most deprived communities, and attendance from this group is consistently over $70 \%$ at all Children's Centres, with these attendees representing the vast majority of Children's Centre clientele, ensuring socio-demographic homogeneity of the appropriate target population across centres (intra-cluster correlation estimate $=0.04$ ).

The primary outcome in the EPICC trial is child cognition (i.e., language, attention and executive function). Since only one study has examined the impact of book-sharing training on executive function [20], and only one trial has reported an outcome for attention [14], we must calculate sample size from the language variable. The most recent meta-analysis [23] included the 10 RCTs of book-sharing interventions that targeted parents of pre-school children and reported the outcome of child expressive language. Although all but one of these studies showed positive benefit to the children's language (the exception was one that comprised just three 5-min sessions [24]), there was considerable variability in the nature and duration of the intervention programmes, and there was significant variability in terms of child outcome [23]. The overall effect size for expressive language in the 10 studies was 0.57 . However, it is too conservative to base the sample size for the current trial on the effect size for all 10 studies, as the average effect size was 0.88 for the three trials that used a group format of dialogic reading instruction of the form to be used in the current study, and the lowest effect size (0.04) was reported in a study involving just 5-min training sessions [24]. A mid-range medium effect size is therefore justified by the previous data. Using the statistical package $\mathrm{R}$, with $d=0.66$, within the cluster design, an index and control sample of 96 carers in each are required (with alpha $=0.05$ and beta $=0.90$ ). With an addition of $10 \%$ to account for sample loss, a total sample of 214 carers is required - i.e., two groups of 107 .

\section{Recruitment}

Recruitment began in April 2017 and ended in November 2017. Recruitment took place in two consecutive waves April to July, and July to November. Recruitment was effected by the study Trial Manager (SJ) approaching parents individually in the Children's Centres, explaining the study to them, and giving them an information sheet.

\section{Randomisation}

Randomisation of the Children's Centres to index and control clusters was undertaken by an independent statistician, with minimisation on the index of multiple deprivation (IMD) and ethnic profile of the wards in which each of the Centres is based.

\section{The intervention, facilitators, training and supervision The training programme}

The training programme is for carers and is designed to promote supportive dialogic book-sharing with young children. The programme is based on one trialled in South Africa and found to be highly effective in improving carer book-sharing skills, and to have significant benefit on child development [13-15]. The programme has been piloted in a UK Children's Centre (Pen Green in Corby) where it was enthusiastically received by both staff and parents. The programme involves parents meeting in small groups (4-6) and receiving instruction from a facilitator over seven, weekly, one-hour sessions. These sessions, which are organised around a "book of the week", involve a Microsoft PowerPoint presentation with demonstration video clips to illustrate key learning points, with book-sharing skills built incrementally. After the first session, each session begins with a review of participants' book-sharing experiences during the preceding week. The group session ends with each parent being given the book to take home to share with their child, with encouragement to do so on a daily basis for approximately $10 \mathrm{~min}$. After the one-hour group session, there is a $5-10$-min period in which each parent shares the book with their own child, under the support and guidance of the facilitator. The content of the seven sessions of the programme is shown in Table 1. It can be seen that, following an introductory session, there are six substantive sessions, with each session framed around specific learning content (e.g., talking about emotions, or about perspectives). Families keep the books they take home each week, and during the 46-month follow up period we send each family a new book on two occasions.

For the current trial, the intervention was delivered by two facilitators - a primary school teacher and an early-years practitioner. They were trained in the intervention during a 3-day workshop run by LM and PJC with the help of David Jeffery, the Chief Executive Officer (CEO) of the Mikhulu Child Development Trust (www.mikhulutrust.org). Both the facilitators ran a practice group before the trial commenced.

Weekly supervision was provided to the facilitators throughout the intervention phase of the study. LM and PJC met with the facilitators for an hour each week to review how the sessions went over the previous week. The two facilitators discussed aspects that went well, challenges, and logistical issues. They also identified any participants who were experiencing difficulties in applying the programme with their child, and discussed the support they may need in their next session. Finally, the 
Table 1 Intervention session content

\begin{tabular}{ll}
\hline Session & Session content \\
\hline 1 & $\begin{array}{l}\text { Introduction to book sharing (using Handa's Surprise by Eileen Browne) } \\
\text { The benefits to child development of book-sharing are explained, and the importance of establishing a book-sharing routine stressed. } \\
\text { Basic principles of dialogic reading are outlined, including following the child's lead, as well as techniques such as pointing and naming } \\
\text { and asking "who/what/where" questions to engage the child and encourage dialogue }\end{array}$ \\
& $\begin{array}{l}\text { Elaborating and linking (using Little Helpers by Lynne Murray, Peter Cooper and Lyn Gilbert) } \\
\text { Picking up on the child's focus of interest and elaborating on it. Making links between the book content and the child's own experience. } \\
\text { Making links between different elements of the book, and their relation to the overall book narrative }\end{array}$ \\
& Numeracy and comparisons (using Handa's Hen by Eileen Browne) \\
& Introducing the idea of counting and comparative concepts (e.g., more, less, highest, smallest) and category inclusion and exclusion \\
& Talking about feelings (using Hug by Jez Alborough) \\
& Talking about the feelings of the book characters. Naming feelings and contextualising them. Linking the book characters' feelings to \\
the child's own emotional experience & \\
& Talking about intentions (using Harry the Dirty Dog by Gene Zion and Margaret Bloy Graham) \\
Discussing why characters feel the way they do, asking what characters are thinking and intending, encouraging the child to be \\
curious about what will come next in the story \\
Talking about perspectives (using Harry by the sea by Gene Zion and Margaret Bloy Graham) \\
Helping the child understand that different people can see things differently, know different things, and feel differently about things \\
Relationships (using The Wrong Side of the Bed by Edward Ardizzone) \\
Discussing family relationships, including conflict and resolution
\end{tabular}

group reviewed the attendance records from the past week and discussed plans for catch up sessions with any participant who may have missed sessions. The number of sessions each participant attended was recorded.

\section{Data collection}

\section{Data collector training}

Two data collectors (AM and AP), both with a Master's degree in Developmental Psychopathology, were trained in the child assessments and caregiver assessments. Training was held over a one-month period and followed a data collector manual developed by LM and PC. During the three assessment waves, LM and PJC make regular checks through examination of the data to ensure fidelity of assessment administration. Both data collectors are familiar with consent and referral procedures and with how to discuss potentially sensitive topics with caregivers during the assessment.

\section{Procedures}

All carer/child pairs are assessed on three occasions: at baseline, following the 7-week intervention, and 4-6 months post-intervention. For the baseline assessment, caregivers are contacted by the Trial Manager (SJ) and the study is explained to them. It is emphasised that participation is entirely voluntary and that non-participation will not affect the service they receive from the Children's Centre. A suitable time for them to come in to the Children's Centre for assessment by the data collector is arranged. On arrival at the assessment session, consent is explained again and caregivers provide consent for both themselves and their child. Assessments take up to $2.5 \mathrm{~h}$. They comprise specific assessments of the child (e.g., the Early Childhood Vigilance Task), questionnaires completed by the caregiver (e.g., the Strengths and Difficulties Questionnaire), and filming the caregiver and child in interactive tasks (e.g., book-sharing). There are breaks for refreshment, and if the child shows any signs of tiredness or distress, the session is interrupted or, if necessary, terminated. Participants are given a small gratuity for contributing their time to the study. Similar procedures are followed for the subsequent two assessment waves. To prevent assessment bias, assessments of children and caregivers are being carried out blind to group allocation, including explicitly asking participants not to reveal their allocation to the data collectors. All coding of video material is made blind to allocation.

\section{Retention}

Provisions have been put in place to maximise participant retention. This includes texts and phone calls to remind participants of scheduled assessments.

\section{Outcomes}

For details of outcomes see Table 2

\section{Assessments}

Independent assessments are being made of index and control participants by the two trained data collectors. These assessments are made in the Children's Centres for the first two assessments (and occasionally in families' homes) and the final assessment is made at the School of Psychology and Clinical Language Sciences of the University of Reading.

The assessments being made are as follows: 
Table 2 Study outcomes and measures

\begin{tabular}{|c|c|c|c|c|c|}
\hline & & & \multirow[b]{2}{*}{ Week 1-4 } & \multicolumn{2}{|c|}{ Post allocation } \\
\hline & & & & Week 18-22 & Week 30-38 \\
\hline Outcomes & Concept & Measures & Baseline & Post & Follow up \\
\hline \multirow{18}{*}{$\begin{array}{l}\text { Child cognitive development } \\
\text { (primary outcome) }\end{array}$} & Language & & & & \\
\hline & \multirow[t]{2}{*}{ Expressive } & $\begin{array}{l}\text { EYT } \\
\text { (expressive vocabulary) }\end{array}$ & $x$ & $x$ & $x$ \\
\hline & & Parent report: CDI & $x$ & $x$ & $x$ \\
\hline & \multirow[t]{2}{*}{ Receptive } & Pre-school CELF-2 & & & $x$ \\
\hline & & Parent report: CDI & $x$ & $x$ & $x$ \\
\hline & \multicolumn{5}{|l|}{ Attention } \\
\hline & & EYT (Go No Go) & $x$ & $x$ & $x$ \\
\hline & & ECVT & $x$ & $x$ & $x$ \\
\hline & & $\begin{array}{l}\text { Observation: } \\
3 \text { toys task }\end{array}$ & $x$ & $x$ & $x$ \\
\hline & & Parent report: SDQ and CSBQ & $x$ & $x$ & $x$ \\
\hline & \multicolumn{5}{|l|}{ Executive function } \\
\hline & $\begin{array}{l}\text { Non-verbal } \\
\text { reasoning }\end{array}$ & WPPSI block design & & $x$ & $x$ \\
\hline & Task shifting & EYT (card sort) & & & $x$ \\
\hline & \multirow{2}{*}{$\begin{array}{l}\text { Phonological } \\
\text { working memory }\end{array}$} & Digit span & & $x$ & $x$ \\
\hline & & Following instructions & & $x$ & $x$ \\
\hline & Persistence and strategies & $\begin{array}{l}\text { Observation: } \\
\text { Lab-TAB }\end{array}$ & $x$ & & $x$ \\
\hline & Inhibition & EYT (Go No Go) & $x$ & $x$ & $x$ \\
\hline & Self- regulation & $\begin{array}{l}\text { Parent report: } \\
\text { CSBQ }\end{array}$ & $x$ & $x$ & $x$ \\
\hline \multirow[t]{4}{*}{$\begin{array}{l}\text { Child social development } \\
\text { (secondary outcome) }\end{array}$} & $\begin{array}{l}\text { Theory of mind and } \\
\text { emotional understanding }\end{array}$ & $\begin{array}{l}\text { Observation: } \\
\text { ToM package }\end{array}$ & $x$ & $x$ & $x$ \\
\hline & Empathy & $\begin{array}{l}\text { Observation: } \\
\text { help task }\end{array}$ & $x$ & $x$ & $x$ \\
\hline & Altruism & $\begin{array}{l}\text { Observation: } \\
\text { token sharing }\end{array}$ & & & $x$ \\
\hline & Pro-social behaviour & $\begin{array}{l}\text { Parent report: } \\
\text { SDQ }\end{array}$ & $x$ & $x$ & $x$ \\
\hline \multirow{2}{*}{\multicolumn{2}{|c|}{$\begin{array}{l}\text { Child behavioural problems } \\
\text { (secondary outcome) }\end{array}$}} & $\begin{array}{l}\text { Observation: } \\
\text { don't touch task }\end{array}$ & $x$ & $x$ & $x$ \\
\hline & & Parental report: SDQ & $x$ & $x$ & $x$ \\
\hline \multicolumn{2}{|l|}{ Child emotion regulation } & Observation: Lab-TAB & $x$ & & $x$ \\
\hline \multicolumn{2}{|l|}{ (secondary outcome) } & $\begin{array}{l}\text { Parent report: } \\
\text { CSBQ }\end{array}$ & $x$ & $x$ & $x$ \\
\hline \multicolumn{2}{|l|}{$\begin{array}{l}\text { Parental sensitivity and reciprocity } \\
\text { (secondary outcome) }\end{array}$} & $\begin{array}{l}\text { Observation: } \\
\text { book-sharing }\end{array}$ & $x$ & $x$ & \\
\hline \multicolumn{2}{|l|}{$\begin{array}{l}\text { Parental cognitive scaffolding } \\
\text { (secondary outcome) }\end{array}$} & $\begin{array}{l}\text { Observation: } \\
\text { book-sharing and puzzle task }\end{array}$ & $x$ & $x$ & \\
\hline \multicolumn{2}{|l|}{$\begin{array}{l}\text { Parental mental state talk } \\
\text { (secondary outcome) }\end{array}$} & Book-sharing & $x$ & $x$ & \\
\hline \multirow{2}{*}{\multicolumn{2}{|c|}{ Parental behavioural management strategies }} & Observation: don't touch task & $x$ & $x$ & $x$ \\
\hline & & Parent report: Discipline Scale & $x$ & $x$ & $x$ \\
\hline
\end{tabular}


Table 2 Study outcomes and measures (Continued)

\begin{tabular}{|c|c|c|c|c|c|}
\hline & & & \multirow[b]{2}{*}{ Week 1-4 } & \multicolumn{2}{|c|}{ Post allocation } \\
\hline & & & & Week 18-22 & Week 30-38 \\
\hline Outcomes & Concept & Measures & Baseline & Post & Follow up \\
\hline \multirow[t]{2}{*}{ Parental stress and mood } & & Parent report: PSI & $x$ & $x$ & $x$ \\
\hline & & $\begin{array}{l}\text { Parent report: } \\
\text { HADS }\end{array}$ & $x$ & $x$ & $x$ \\
\hline
\end{tabular}

Abbreviations: EYT Early Years Toolbox, CDI Communication Development Inventory, CELF Clinical Evaluation of Language Fundamentals, ECVT Early Child Vigilance Task, SDQ Strengths and Difficulties Questionnaire, WPPSI Wechsler Preschool and Primary Scale of Intelligence, Lab-TAB Laboratory Temperament Assessment Battery, CSBQ Child Self-Regulation and Behaviour Questionnaire, PSI Parenting Stress Index, HADS Hospital Anxiety and Depression Scale

\section{Child outcomes}

\section{Cognitive development (primary outcome)}

Language: expressive language is being assessed using the Early Years Toolbox (EYT) [20], administered using iPad technology, and receptive language using the Clinical Evaluation of Language Fundamentals (CELF-2) [25]. A parental report measure of language is also being administered, the Communication Development Inventory (CDI) [26].

Attention: this is assessed by deriving an index from the Go-No-Go sub-test of the EYT, by the Early Child Vigilance Task (ECVT) [27], and by observing behaviour in "the three toys" task $[13,28]$, and by parent report on the Strengths and Difficulties Scale (SDQ) [29] and the Child Self-Regulation and Behaviour Questionnaire (CSBQ) of the EYT [20].

Executive function: this is being assessed using the EYT, Block design (WPPSI-IV) [30], Digit span [31], the Following Instructions task [32], and persistence and strategies in the Frustration task of the Laboratory Temperament Assessment Battery (Lab-TAB) [33], and by parent report on the CSBQ [20].

\section{Child social development (secondary outcome)}

Theory of mind and emotional understanding: this is being assessed using a battery of tasks based on Wellman and Liu [34], Hughes et al. [35] and Denham [36]. These tasks comprise brief, typically puppet-enacted scenarios, during which young children are asked to judge the different perspectives, knowledge, desires and emotions of the characters.

Empathy: a "help task" paradigm is being administered in which a researcher feigns experiencing a problem (i.e., being unable to find something that is in view of the child) and the child's response is observed [15, 37, 38].

Altruism: a modified version of an altruism task [39] is being used.

Prosocial behaviour: this is being measured by parent report using the SDQ [29].

\section{Child behaviour problems (secondary outcome)}

These are being assessed by maternal report and direct observation. For maternal report we are using the SDQ [29]. Child behaviour is also assessed by direct observation during the parent-child interactions in the "don't touch" task (in which the child is prohibited from touching attractive toys) [40-42].

\section{Emotion regulation (secondary outcome)}

This is being assessed by direct observation using the Distress-Anger/Frustration component of the Lab-TAB for pre-school children, and by parent report on the CSBQ [20].

\section{Parenting (secondary outcome)}

Sensitivity and reciprocity $[13,15]$ and cognitive scaffolding are being assessed by direct observation of parent-child interaction in book-sharing and a problem solving task. Mental state talk is also assessed during book-sharing.

Parent behaviour management strategies: these are being assessed by maternal report and direct observation. Parents complete the Child Rearing Discipline Scale [43], and they are directly observed during the "do not touch" task described above [39, 43].

\section{Potential moderators}

The following variables will be used as potential moderators: family socio-economic status, parental education, monolingualism status, ethnic group, parental mental health (HADS; [44]), stress (PSI [45]), and baseline book-sharing, child sex, age and birth order.

\section{Data management}

Data are submitted to a secure University server. Participants are allocated personal identification numbers that are used in all study records to protect their identity and maintain confidentiality. All child assessments and caregiver-child interaction tasks are video-recorded, for 
both coding and quality control purposes. Videos are labelled by the assessors and saved on the secure server at the end of each day.

\section{Data analysis}

Data analysis will be completed by a designated statistician independent from study investigators. Group baseline differences will be assessed using the independent samples $t$ test, Mann-Whitney $\mathrm{U}$ test, and chi-squared test. Analysis of baseline group differences will include socio-demographic data, such as child sex, and household factors (e.g., income, relationship status). The primary and secondary outcomes will be analysed using linear mixed models which can account for clustering of individuals within the Children's Centre and for repeated assessments within individuals (for outcomes measured at multiple time points). Intervention effects will be assessed post intervention and at follow-up, and will be adjusted for the child's age, sex and baseline scores (where applicable). Further socio-demographic factors may also be investigated as covariates. If the necessary assumptions of the models do not hold, suitable alternative models will be fitted. Intention-to-treat analysis will be used to examine intervention effects [45]. The amount and pattern of missing data will be examined and will be addressed using multiple imputation where appropriate.

\section{Mediator analyses}

Mediator analyses will aim to identify active components of the intervention and elucidate the pathways to change. To this end, the following three questions will be examined: whether improvements in maternal sensitivity and reciprocity and cognitive scaffolding mediate improvements in child cognition; whether increases in maternal sensitivity, reciprocity and mental state talk mediate improvements in child social understanding; and whether increases in maternal sensitivity, reciprocity and mental state talk and improved behaviour management strategies mediate improvements in child behaviour, and emotional regulation.

\section{Moderator analyses}

Moderator analyses will be conducted to investigate whether certain groups respond differently to the intervention. In addition to the potential moderators listed above, we will examine the impact of number of intervention sessions attended. Potential mediators and moderators of the intervention will be examined using mixed linear models or structured equation modelling, as appropriate.

\section{Trial monitoring}

\section{Trial Steering Committee}

An independent Trial Steering Committee (TSC) monitors the progress of the trial and advises the research team on matters arising during the course of the study. The TSC meets bi-annually. The TSC is chaired by a Professor of Education from Oxford University. Its other members, in addition to the four Principal Investigators (PIs)/co-PIs (LM, PJC, CH, EM) and the Trial Manager (SJ), are a parent and representatives of children's advocacy groups (Action for Children and the Foundation Years Trust). If the assessors, the facilitators, or the Trial Manager have concerns about the children or the carers, they inform the Reading PIs (LM/PJC) who take appropriate steps to address the problem.

\section{Discussion}

The EPICC trial is an evaluation of an intervention in which carers of young children who are attending a Children's Centre are provided with training over 7 weeks in dialogic picture-book sharing with their child, following a specific manualised programme. The trial aims to evaluate the impact of this early parenting intervention on child cognition (i.e., language, attention and executive function). Its impact will also be evaluated on child social development (i.e., theory of mind and social understanding, empathy, altruism and pro-social behaviour), behavioural problems, and emotional regulation. Effects on parenting will also be assessed - i.e., sensitivity, reciprocity, cognitive scaffolding, mental state talk, and behavioural management strategies. The study is being carried out in UK Children's Centres. Since the intervention is brief and readily deliverable with modest levels of training, demonstration of benefit to child cognitive and socio-emotional development would be important. This study is similar in its methodology to a dialogical book-sharing trial currently being conducted in a poor community in South Africa [46].

\section{Dissemination plans \\ Outcomes, outputs and dissemination}

Following receipt of the trial statistical report, we will disseminate the study findings in several ways. We will publish them in major peer reviewed academic journals and in relevant professional journals. We will produce a summary of the project's objectives, methodologies and key findings, together with recommendations for policy and practice, which will appear on the University of Reading website. We will also write a briefing paper for distribution to the Department for Education (specifically the Minister for Children and his/her policy team), the Local Government Association, Confederation of Scottish Local Authorities, the European Social network and to a range of early years associations/ 
non-governmental organisations (NGOs) (e.g., Save the Children, Barnardo's, Action for Children, National Childbirth Trust (NCB)) and the media. It is likely that this will lead to press, radio and TV coverage of the findings. We will make oral presentations at psychology, education and professional organisation conferences, both nationally and internationally, and together with our media coverage this will engage the attention of parents and other interested groups. Finally, we will hold an end of study workshop. This workshop will include the $\mathrm{PI} / \mathrm{co}-\mathrm{PIs}$ (LM, PJC, CH, EM) and the Steering Committee members, together with policy makers from the DfE and Local Authorities and academics and practitioners with special interest and expertise in this area. Through the research team's involvement (and particularly that of EM), with international policy agencies, such as the Organisation for Economic Cooperation and Development (OECD), the WHO, and the European Commission, opportunities for international impact will likely emerge. To ensure the possibility of scale up, LM and PC will provide the dialogic book-sharing training materials to key stake-holder organisations on request and, via the Mikhulu Trust, will support the provision of courses in the training programme and accreditation of trainers.

\section{Trial status}

At the point of submitting this manuscript to the journal (30 October 2017) 212/214 of the sample had been recruited. This paper represents version 1 of the protocol.

\section{Additional file}

Additional file 1: SPIRIT 2013 Checklist: Recommended items to address in a clinical trial protocol and related documents. (DOCX $63 \mathrm{~kb}$ )

\begin{abstract}
Abbreviations
CDI: Communication Development Inventory; CELF: Clinical Evaluation of Language Fundamentals; CEO: Chief Executive Officer; CSBQ: Child SelfRegulation and Behaviour Questionnaire; DfE: Department for Education; ECVT: Early Child Vigilance Task; EPICC: Early-years Provision of Care in Children's Centres; EYT: Early Years Toolbox; HADS: Hospital Anxiety and Depression Scale; IDACI: Indices of Deprivation Affecting Children; IMD: Index of Multiple Deprivation; ISRCTN: International standard randomised controlled trials number; Lab-TAB: Laboratory Temperament Assessment Battery; LSOA: Local super output area; NCT: National Childbirth Trust; OECD: Organisation for Economic Cooperation and Development; PSI: Parenting Stress Index; RCT: Randomised controlled trial; SDQ: Strengths and Difficulties Questionnaire; TSC: Trial Steering Committee;

UREC: University of Reading Research Ethics Committee; WHO: World Health Organisation; WPPSI: Wechsler Preschool and Primary Scale of Intelligence
\end{abstract}

\section{Acknowledgements}

The study is sponsored by The University of Reading in the UK. We are grateful to Katherine De Wilde and Martin Andrews for carrying out the intervention, and to Jack Dainty for assistance with randomisation, and to Hayley Perry for guidance on the data analytic strategy. We are also very grateful to the staff of all the Reading Children's Centres for their support and assistance in carrying out the EPICC study. Finally, we wish to express our sincere thanks to the families taking part in the research.

\section{Funding}

The EPICC trial is funded by the Nuffield Foundation with additional support from the MRC Cognition and Brain Sciences Unit.

\section{Availability of data and materials}

Datasets will be deposited in publicly available repositories (where available and appropriate) one year after the completion of the study.

\section{Authors' contributions}

LM and PJC developed the intervention, designed the study and are supervising all aspects of its implementation. $\mathrm{CH}$ and EM are co-Pls and have assisted with particular aspects of the assessment protocol, as have JD and $J \mathrm{H}$. CD has liaised between the trial team and the Children's Centres. SJ is the Trial Manager and AJ and AP are the trial assessors. All authors read and approved the final manuscript.

\section{Ethics approval and consent to participate}

Ethical approval for the EPICC trial was obtained from the University of Reading Research Ethics Committee (reference number N15/09/084). Any modifications to the study protocol will be communicated to the UREC, and updated on the trial registry. Participation in the EPICC trial is dependent on the informed consent of the primary caregiver of the child.

\section{Competing interests}

The authors declare that they have no competing interests.

\section{Publisher's Note}

Springer Nature remains neutral with regard to jurisdictional claims in published maps and institutional affiliations.

\section{Author details}

${ }^{1}$ University of Reading, Reading, UK. ${ }^{2}$ Stellenbosch University, and the University of Cape Town, Stellenbosch, South Africa. ${ }^{3}$ University of Oxford, Oxford, UK. ${ }^{4}$ University of Cambridge, Cambridge, UK. ${ }^{5}$ MRC Cognition and Brain Sciences Unit, Cambridge, UK. ${ }^{6}$ Reading Borough Council, Reading, UK.

Received: 30 October 2017 Accepted: 18 May 2018

Published online: 22 August 2018

\section{References}

1. Department for Education. Early years pupil premium and funding for twoyear-olds. London: Department for Education; 2014. p. p3.

2. Sutton Trust \& Oxford University. Sound foundations: a review of the research evidence on quality of early childhood education and care for children under three - implications for policy and practice. Oxford: Oxford University; 2014

3. Sylva K. The role of families and pre-school in educational disadvantage. Oxf Rev Educ. 2014;40:680-95.

4. Sammons P, Tot K, Sylva K, Melhuish E, Siraj I, Taggart BL. The long-term role of the home learning environment in shaping students' academic attainment in secondary school. J Children's Serv. 2015;10(3):189-201.

5. Melhuish EC, Sylva K, Sammons P, Siraj-Blatchford I, Taggart B, Phan M. Effects of the home learning environment and preschool center experience upon literacy and numeracy development in early primary school. J Soc Issues. 2008;64:95-114.

6. Centre for Social Justice: Closing the divide: tackling educational inequality in England. 2014.

7. Allen G. Early intervention: the next steps. London: Cabinet Office; 2014. p. p23.

8. Department for Education. Evaluation of the Graduate Leader Fund final report. London: Department for Education; 2011.

9. Mol SE, Bus AG, de Jong MT, Smeets DJ. Added value of dialogic parentchild book readings: a meta-analysis. Early Educ Dev. 2008;19:7-26.

10. Arnold DH, Lonigan CJ, Whitehurst GJ, Epstein JN. Accelerating language development through picture book reading: replication and extension to a videotape training format. J Educ Psychol. 1994;86:235-43.

11. Sénéchal M. The differential effect of storybook reading on preschoolers' acquisition of expressive and receptive vocabulary. J Child Lang. 1997;24:123-38.

12. Whitehurst GJ, Epstein JN, Angell AL, Payne AC, Crone DA, Fischel JE. Outcomes of an emergent literacy intervention in head start. J Educ Psychol. 1994;86(4):542. 
13. Cooper PJ, Vally Z, Cooper H, Radford T, Sharples A, Tomlinson M, Murray L. Promoting mother-infant book sharing and infant attention and language development in an impoverished south African population: a pilot study. Early Childhood Educ J. 2014;42:143-52.

14. Vally Z, Murray L, Tomlinson M, Cooper PJ. The impact of dialogic booksharing on training on infant language and attention: a randomized controlled trial in a deprived south African community. J Child Psychol Psychiatry. 2015;56(8):865-73.

15. Murray L, De Pascalis L, Tomlinson M, Vally Z, Dadomo H, MacLachlan B, Woodward C, Cooper PJ. Randomized controlled trial of a book-sharing intervention in a deprived south African community: effects on carer-infant interactions, and their relation to infant cognitive and socio-emotional outcome. J Child Psychol Psychiatry. 2016;57(12):1370-9.

16. Adrian J, Clemente R, Villanueva L, Rieffe C. Parent-child picture book reading, mothers' mental state language and children's theory of mind. J Child Lang. 2005;32:673-86.

17. Dunn J, Brown J, Beardsall L. Family talk about feeling states and children's later understanding of others' emotions. Dev Psychol. 1991;27:448-55.

18. Dyer J, Shatz M, Wellman H. Young children's story books as a source of mental state information. Cogn Dev. 2000;15:17-37.

19. Ruffman T, Slade L, Crowe E. The relation between children's and mothers' mental state language and theory of mind understanding. Child Dev. 2002; 73:734-51.

20. Howard S, Melhuish E. An early years toolbox (EYT) for assessing early executive function, language, self-regulation, and social development: validity, reliability, and preliminary norms. J Psychoeduc Assess. 2016;35(3):1-21.

21. Maisey R, Poole E, Chanfreau J, Fry A. Children's Centres evaluation in England strand 2: longitudinal survey of families using Children's Centres in the most disadvantaged areas. DfE Research Report 2015: DFE-RR434. London.

22. National IDACI Index. 2015. https://www.northamptonshireanalysis.co.uk/ linked-data/id/indicator/IDACINationalDectile.

23. Dowdall N. The effectiveness of shared picture book reading interventions on child language outcomes: a systematic review and meta-analysis: Masters Thesis, Oxford University; 2015.

24. Goldfeld S, Quach J, Nicholls R, Reilly S, Ukoumunne OC, Wake M. Four-yearold outcomes of a universal infant-toddler shared reading intervention: the Let's read trial. Arch Pediatr Adolesc Med. 2012;166(11):1045-52.

25. Wiig EH, Secord WA, Semel E. Clinical evaluation of language fundamentals - preschool, second edition (CELF Preschool-2). Toronto: The Psychological Corporation/A Harcourt Assessment; 2004.

26. Fenson L, Pethick S, Renda C, Cox JL, Dale PS, Reznick JS. Short form versions of the MacArthur communicative development inventories. Appl Psycholinguist. 2000;21:95-115.

27. Goldman DZ, Shapiro EG, Nelson CA. Measurement of vigilance in 2-yearold children. Dev Neuropsychol. 2004;25(3):227-50.

28. Kannass KN, Oakes LM, Shaddy DJ. A longitudinal investigation of the development of attention and distractibility. J Cogn Dev. 2006;7(3):381-409.

29. Goodman R. Psychometric properties of the strengths and difficulties questionnaire. J Am Acad Child Adolesc Psychiatry. 2001;40:1337-45.

30. Wechsler D. Wechsler preschool and primary scale of intelligence - fourth edition: manual. Toronto: Pearson Canada Assessment; 2012.

31. Alloway TP. Automated working memory assessment: manual. Toronto: Pearson Canada Assessment; 2007

32. Jaroslawska AJ, Gathercole SE, Logie MR, Holmes J. Following instructions in a virtual school: does working memory play a role? Mem Cogn. 2016;44: 580-9.

33. Goldsmith $\mathrm{HH}$, Rothbart MK. Prelocomotor and Locomotor Laboratory Temperament Assessment Battery, Lab-TAB; version 3.0. Technical Manual. Madison: Department of Psychology, University of Wisconsin; 1996.

34. Wellman HM, Liu D. Scaling of theory-of-mind tasks. Child Dev. 2004;75(2): 523-41.

35. Hughes C, Ensor R, Marks A. Individual differences in false belief understanding are stable from 3 to 6 years of age and predict children's mental state talk with school friends. J Exp Child Psychol. 2011;108:96-112.

36. Denham SA. Social cognition, prosocial behaviour, and emotion in preschoolers: contextual validation. Child Dev. 1986;57:194-201.

37. Dunfield KA, Kuhlmeier VA. Classifying prosocial behavior: children's responses to instrumental need, emotional distress, and material desire. Child Dev. 2013:84(5):1766-76.
38. Buttleman D, Carpenter M, Tomasello M. Eighteen-month-old infants show false belief understanding in an active paradigm. Cognition. 2009;112:337-42.

39. Benenson JF, Pascoe J, Radmore N. Children's altruistic behaviour in the dictator game. Evol Hum Behav. 2007:28:168-75.

40. NICHD Early Child Care Research Network Early child care and self-control, compliance, and problem behavior at twenty-four and thirty-six months. Child Dev 1998, 69(4):1145-1170. doi: https://doi.org/10.2307/1132367.

41. Kochanska G, N/ A. Mother-child mutually positive affect, the quality of child compliance to requests and prohibitions, and maternal control as correlates of early internalization. Child Dev. 1995;66(1):236-54.

42. Lansford JE, Deater-Deckard K. Childrearing discipline and violence in developing countries. Child Dev. 2012;83(1):62-75.

43. Zigmond AS, Snaith RP. The hospital anxiety and depression scale. Acta Psychiatr Scand. 1983;67(6):361-70.

44. Abidin RR. Parenting stress index-short form. Charlottesville: Pediatric Psychology Press; 1990.

45. Hollis S, Campbell F. What is meant by intention to treat analysis? Survey of published randomised controlled trials. BMJ. 1999;319(7211):670-4.

46. Dowdall N, Cooper PJ, Tomlinson M, Skeen S, Gardner F, Murray L. The benefits of early book sharing (BEBS) study: protocol of a randomised controlled trial conducted in South Africa of a book sharing intervention to improve child cognitive and socio-emotional development. Trials. 2017:18: $118-31$

\section{Ready to submit your research? Choose BMC and benefit from:}

- fast, convenient online submission

- thorough peer review by experienced researchers in your field

- rapid publication on acceptance

- support for research data, including large and complex data types

- gold Open Access which fosters wider collaboration and increased citations

- maximum visibility for your research: over $100 \mathrm{M}$ website views per year

At BMC, research is always in progress.

Learn more biomedcentral.com/submissions 